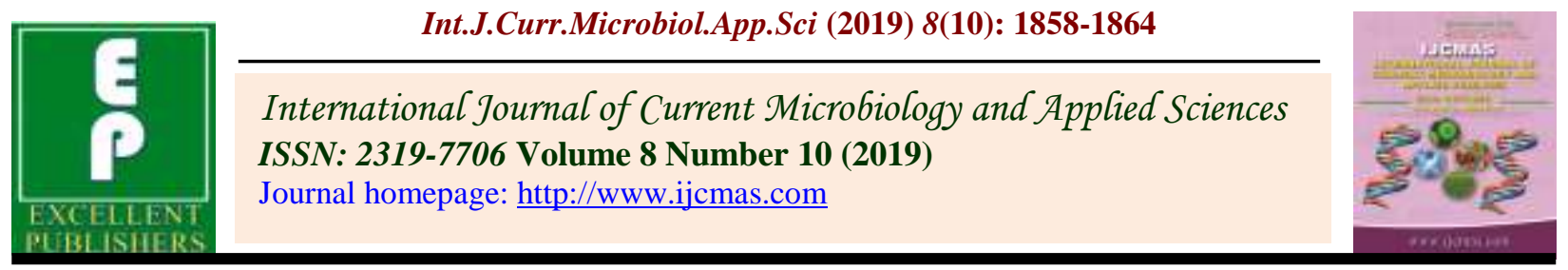

Original Research Article

https://doi.org/10.20546/ijcmas.2019.810.216

\title{
Effect of Different Level of Natural Antioxidant Pomegranate Peel Extract Powder in Instant Functional Chicken Noodles
}

\author{
M. Pavan*, T. Sathu, B. Sunil, C. T. Sathian, V. N. Vasudevan, \\ A. Irshad and S. Kiran Kumar \\ Department of Livestock Products Technology and Meat Technology Unit, College of \\ Veterinary and Animal Sciences, Mannuthy, Kerala-680 651, India \\ *Corresponding author
}

\begin{tabular}{|l|}
\hline K e y w o r d s \\
Pomegranate peel \\
extract powder, \\
Chicken, Noodles, \\
Texture, Sensory \\
and colour
\end{tabular}

A B S T R A C T

The noodles because of its variety, mouthfeel, versatility, convenience to use, it is widely accepted throughout the world and is relished by the people of all age group. But, the current study was conducted to incorporate Pomegranate peel extract powder (PG) at 3 different level viz., 0.5, 1 and 1.5 percent was added over and above the control chicken noodle formulation respectively. The dough $\mathrm{pH}$, product $\mathrm{pH}$, water activity and product yield did not show any significant difference between $\mathrm{T}_{1}, \mathrm{~T}_{2}$ and $\mathrm{T}_{3}$ and were in the range of $7.382-7.390,7.392-7.398,0.501-0.510$ and $95.329-$ 95.662 respectively. The Water Absorption Index and Swelling Power Index decreased significantly $(\mathrm{p}<0.05)$ with the rise in concentration of $P G$, the treatment $T_{3}$ had significantly $(\mathrm{p}<0.05)$ lower WAI and SPI than $\mathrm{T}_{2}$ and $\mathrm{T}_{3}$. The lightness and redness value significantly $(\mathrm{p}<0.001)$ decreased with the increase in concentration of PG in chicken noodles and yellowness did not show any significant difference between the test samples. The $T_{3}$ had significantly $(p<0.001)$ lower lightness values than all the test samples. The flavour, taste, softness and mouth coating scores were significantly $(\mathrm{p}<0.001)$ lower for $\mathrm{T}_{3}$. The panellists opined that the chicken noodles with PG incorporation at level above 0.5 per cent adversely affected the flavour, taste, softness and also overall acceptability.

\section{Introduction}

The origin of the Noodle was first in Japan during 1950s. Noodles are generally prepared using various types of flours, water and salt usually cooked in soup or boiling water. Noodles are long thin piece of food made from unleavened dough from different types of ingredients. The instant noodles are the type of noodles precooked in oil or steam cooked and dried and marketed with packet of flavouring agent and consumed by all the age group of people both in urban and rural areas of the country. The synthetic antioxidants such as butylated hydroxyl anisole (BHA), butylated hydroxyl toluene (BHT), propyl gallate and 
tertiary butyl hydroxyl quenone (TBHQ) are used in meat and meat products are known to exhibit various health effects.

The prolonged use of such synthetic chemicals can induce health hazards such as teratogenic and carcinogenic effects in laboratory animals and primates (Hathway, 1966). Because of these type of problems associated with synthetic antioxidants the current study was conducted to use natural antioxidant pomegranate peel extact powder in chicken noodles. Pomegranate fruit arils can be used to prepare flavoured juice, squash, jelly, wine, anardhana, etc and recently in chewing gum, jelly, ice cream and truffles. During the production of this type of products, Pomegranate peel waste disposal becomes a big problem and hence the powdered form is used in meat products which are likely to have more bioactive compounds than the pulp fractions (Balasundharan et al., 2006). Pomegranate can be used for medicinal purposes and are used in the treatment of inflammatory disease and disorders of the digestive tract (Lansky and Newman, 2007).

Keeping in view all the above facts, the present study was envisaged to attempt the use ofPG as natural antioxidantin the development of functional meat products, a study was designed to evaluate the effect of different levels of PG powder at 3 different level viz, $0.5,1$ and 1.5 percent respectively on physicochemical properties, water hydration and sensory profile of noodles containing $70 \%$ chicken over and above the formulation.

\section{Materials and Methods}

\section{Chicken}

Spent chicken of 1.5 to $1.75 \mathrm{~kg}$ live body weight procured from the local market were scientifically slaughtered and dressed under hygienic conditions at Meat Technology Unit,
Mannuthy. The dressed carcasses were stored under freezer conditions at $\left(-23 \pm 1^{\circ} \mathrm{C}\right)$ until thawed at $4 \pm 1^{\circ} \mathrm{C}$ before used for preparation of noodles. The dressed spent chicken is pressure cooked and deboned. The deboned chicken meat is minced in mincer (MADO primus Model MEW 613, Germany) for three times using $6 \mathrm{~mm}$ plate and mixed with control formulation.

\section{Vegetable oil}

Refined sunflower oil (Sundrop) was used throughout the study for frying.

\section{Spice mixture}

A spice mix was prepared in the department specially for chicken noodles was used.

\section{Natural Antioxidants}

Pomegranate peel extract powder, PL99800, from Plant Lipids Private Limited, Cochin, Kerala.

The formulation of control noodles was standardized by conducting several trials. The standardized control formulation was used for the entire studies (Table 1).

\section{Preparation of Control Noodles}

The ingredients such as wheat flour, rice flour, maida flour, salt, sodium bicarbonate, potato starch, wheat gluten, guar gum and polyphosphates were used in the formulation of control noodles. Several trials were conducted to standardize the flour and chicken per cent in the control formulation. The sodium bicarbonate, potato starch, wheat gluten, guar gum and polyphosphates were mixed separately in hot water and then added to the flour mix. The flour mix prepared is put in to the "automatic pasta making machine" Dolly GB (Italy), and is kneaded for $10 \mathrm{~min}$ 
and water is added to it at $33 \%$ of control flour formulation and approximately $12 \%$ of chicken stock solution in chicken noodles to make dough of proper consistency and extruded.

The prepared raw noodles were then deep fat fried in sunflower oil at $180^{\circ} \mathrm{C}$ in electric single tank fryer. (Toastmaster model no. EDZ-4L) for 45 seconds and then dried in hot air oven at $100^{\circ} \mathrm{C}$ for $30 \mathrm{~min}$. The dried noodles were cooled at room temperature and then packed aerobically in laminated pouches (PE/AL/PA) and stored in dry place at ambient temperature.

\section{Quality parameters analysed}

\section{pH}

The dough $\mathrm{pH}$ and the product $\mathrm{pH}$ of the noodles from all the treatments and control, was determined using a combined electrode digital $\mathrm{pH}$ meter $(\mu \mathrm{pH}$ system 362, Systronics, India) as per procedure of AOAC (2012).

\section{Water activity(a $\left(\mathbf{a}^{\mathrm{w}}\right)$}

For determination of $a_{w}$, the samples were cut into small pieces and filled in the sample cup up to the mark. The filled sample cup was kept in the measurement chamber of Lab swift $a_{w}$ meter (Novasina, Switzerland). The readings were taken, when the stable $\mathrm{a}_{\mathrm{w}}$ was on in the display (Cabonell et al., 2005).

\section{Cooking yield percentage}

The weights of fresh extruded noodles before and after frying stage of preparation were recorded. Product yield was expressed in percentage. The fried noodles are referred as raw noodles throughout this thesis (Berry et al., 1992).
Cooking yield (\%)

$=\underline{\text { Weight }}$ of extruded fried noodles $\times 100$

Weight of fresh extruded noodles

\section{Water hydration properties}

The water absorption index (WAI), water solubility index (WSI)and swelling power index (SPI) of the rice flour samples were determined according to a reported method (Ohishi et al., 2007) with slight modifications. $1 \mathrm{~g}$ raw noodle was dispersed in $20 \mathrm{~mL}$ deionized water and agitated at $25^{\circ} \mathrm{C}$ and $100^{\circ} \mathrm{C}$ for $30 \mathrm{~min}$, respectively. After centrifuging the dispersion at 15,000 $\mathrm{g}$ for 30 min, the supernatant was dried in a hot air oven at $105^{\circ} \mathrm{C}$ until a constant weight was obtained. WAI, WSI and SPI were calculated by the following formulae.

WAI $=$ Wet sediment weight $/$ dry sample weight

WSI $=($ Dry supernatant weight / dry sample weight $) \times 100$

SPI $=($ Wet sediment weight $\times 100 /$ Dry sample weight (100 - dry supernatant)

\section{Colour parameters}

Colour of the steam raw noodles sample was determined objectively as per Page et al., (2001) using Hunter Lab Mini Scan XE Plus Spectrophotometer (Hunter Lab, Virginia, USA) with diffuse illumination. The instrument was set to measure Hunter $\mathrm{L}^{*}, \mathrm{a}^{*}$ and $\mathrm{b}^{*}$ using illuminant $45 / 0$ and $10^{\circ}$ standard observer with an aperture size of $2.54 \mathrm{~cm}$. It was calibrated using black and white calibration tiles before starting of the measurement and colorimeter score recorded with ' $L$ ' of black equals zero and ' $L$ ' of white equals 100, 'a' of lower numbers equals more green (less red), higher numbers equals more red (less green) and ' $b$ ' of lower numbers 
equals more blue (less yellow), higher numbers equals yellow (less blue). The colour coordinates $\mathrm{L}^{*}$ (lightness), $\mathrm{a}^{*}$ (redness) and $\mathrm{b}^{*}$ (yellowness) of the samples were measured thrice and mean values were taken.

\section{Sensory evaluation}

The sensory evaluation was conducted by serving hot noodles cooked with the spice mix (4gm) that was developed in the department. $70 \mathrm{gm}$ of noodles was cooked in $420 \mathrm{ml}$ for 10 minutes at $120^{\circ} \mathrm{C}$ in an induction cooker. The Sensory attributes of the noodles were assessed organoleptically using 8 point Hedonic scale score card with the help of seven semi-trained taste panelists drawn from the Department of Livestock Products Technology, Mannuthy, Thrissur, Kerala, India. The average of the individual scores was taken as the score for the particular attribute (Sirichokworrakit et al., 2015).

\section{Results and Discussion}

$\mathrm{T}_{1}, \mathrm{~T}_{2}$ and $\mathrm{T}_{3}$ samples were prepared by incorporating $\mathrm{PG}$ at level 0.5 per cent, 1 per cent and 1.5 per cent respectively. The best level of natural antioxidant (PG) was selected primarily based on the physico-chemical properties, water hydration, colour values and sensory attributes.

\section{Physico-chemical properties}

The physico-chemical properties of the functional chicken noodles with addition of different levels of pomegranate rind extract powder (PG) in $\mathrm{T}_{1}, \mathrm{~T}_{2}$ and $\mathrm{T}_{3}$ at 0.5 per cent, 1 per cent and 1.5 per cent respectively are presented in Table 2.

The dough $\mathrm{pH}$ and the product $\mathrm{pH}$ did not show any significant difference between $T_{1}$, $\mathrm{T}_{2}$ and $\mathrm{T}_{3}$ and were in the range of $7.382-$ 7.390 and $7.392-7.398$, respectively. In
Naveena et al., (2008) work the $\mathrm{pH}$ of cooked chicken patties was found to be $6.38-6.10$ at different level of incorporation of $\mathrm{PG}$ rind powder as antioxidants. Whereas, the water activity and frying yield did not show any significant difference between $T_{1}, T_{2}$ and $T_{3}$ and were in the range of $0.501-0.510$ and 95.329 - 95.662 respectively. Naveena et al.,(2008) found reduced water activity with rise in the pomegranate rind powder extract addition. Banerjee et al., (2012), found no variation in the product yield of the barcoli powder extract added goat meat nuggets.

\section{Water hydration properties}

The Water Hydration Properties of the functional chicken noodles with addition of different levels of pomegranate rind extract powderare presented in Table 3. The Water Absorption Index and Swelling Power Index decreased significantly $(p<0.05)$ with the rise in concentration of $\mathrm{PG}$, the treatment $\mathrm{T}_{3}$ had significantly $(\mathrm{p}<0.05)$ lower WAI and SPI than $T_{2}$ and $T_{3}$. Water Solubility Index did not vary significantly among them. Similarly, Wang et al., (2004) reported that the extract of green tea as natural antioxidant at certain percentages could weaken the gluten matrix in bread texture quality affected water absorption property. But,

\section{Colour ( $\mathbf{L} * \mathbf{a} * \mathbf{b} *$ values $)$}

The Colour parameters of the functional chicken noodles with addition of different levels of PG at 0.5 per cent, 1per cent and 1.5 per cent respectively are presented in Table 2.

The lightness and redness value significantly $(\mathrm{p}<0.001)$ decreased with the increase in concentration of PG in chicken noodles and yellowness did not show any significant difference between the test samples. The $\mathrm{T}_{3}$ had significantly $(\mathrm{p}<0.001)$ lower lightness 
values than all the test samples. Qin et al., (2013) found lower lightness (L*), higher redness and reduction in yellowness in ground pork meat incorporated with pomegranate rind powder extract, pomegranate juice and Pomegranate Seed Powder Extract. In contrast to this result Banerjee et al., (2012) found no significant difference in redness, yellowness and hue values among chicken nuggets incorporated with different levels of broccoli powder extract.

\section{Sensory evaluation}

The sensory evaluation of chicken noodles incorporated with pomegranate peel extract powder is represented in Table 3.

The sensory evaluation of chicken noodles with pomegranate rind extract powder did not show any significant difference in appearance and colour, stickiness and mouth coating scores of chicken noodles. The PG incorporation disturbed the texture of $\mathrm{T}_{2}$ and $\mathrm{T}_{3}$ and also added black colour to the noodles even at 0.5 per cent and hence the scores of appearance and colour were less for $\mathrm{T}_{2}$ and $\mathrm{T}_{3}$. The flavour, taste, softness and mouth coating scores were significantly $(p<0.001)$ lower for
$\mathrm{T}_{3}$. The panellists opined that the chicken noodles with PG incorporation at level above 0.5 per cent adversely affected the flavour, taste, softness and also overall acceptability. Naveena et al., (2008) reported no significant difference was observed for chicken flavor and overall acceptability in chicken nuggets on addition of PG peel extract powder as natural antioxidant in chicken meat patties.

The results of Pomegranate peel extract powder at 0.5 and 1 per cent and 1.5 per cent level in chicken noodles revealed that 0.5 percent of PG is the optimum level to be incorporated in the chicken noodle. Sensory evaluation also revealed that the PG incorporation disturbed the texture of $\mathrm{T}_{2}$ and $\mathrm{T}_{3}$ and also added black colour to the noodles even at 0.5 per cent. Addition of PG at higher level than 0.5 percent can effect the texture and reduce the water hydration properties.

Thus maximum level of pomegranate peel extract powder that can be incorporated in chicken noodles is 0.5 per cent and above this level adversely affecting the most of the sensory attributes.

Table.1 Formulary for the preparation of control noodles

Ingredients

I. 1. Chicken

2. Maida flour

3. Wheat flour

4. Rice flour

II. 1. Salt

2. Sodium bicarbonate

3. Potato Starch

4. Wheat gluten

5. Guar gum

Polyphosphate
Control Noodles (\%)
$41.18 \%$
$29.48 \%$
$14.7 \%$
$14.7 \%$
$3 \%$
$0.5 \%$
$5 \%$
$0.4 \%$
$0.2 \%$
$0.2 \%$

*Pomegranate rind extract powder and II were added over and above the standardised control formulation of I. 
Table.2 Physico- chemical, water hydration and colour parameters of the instant chicken noodles

\begin{tabular}{|c|c|c|c|c|c|}
\hline Treatments & $T_{1}$ & $\mathbf{T}_{2}$ & $\mathbf{T}_{3}$ & F- Value & p-Value \\
\hline Dough pH & $7.390 \pm 0.020$ & $7.348 \pm 0.037$ & $7.382 \pm 0.020$ & $0.684^{\mathrm{ns}}$ & 0.520 \\
\hline Product pH & $7.392 \pm 0.062$ & $7.390 \pm 0.009$ & $7.398 \pm 0.015$ & $0.0140^{\mathrm{ns}}$ & 0.986 \\
\hline $\begin{array}{l}\text { Water } \\
\text { Activity }\end{array}$ & $0.510 \pm 0.001$ & $0.509 \pm 0.003$ & $0.501 \pm 0.002$ & $0.059^{\text {ns }}$ & 0.943 \\
\hline Frying yeild & $95.329 \pm 0.277$ & $95.622 \pm 0.084$ & $95.561 \pm 0.093$ & $0.772^{\mathrm{ns}}$ & 0.479 \\
\hline WAI & $3.652 \pm 0.162^{\mathrm{a}}$ & $3.283 \pm 0.063^{b}$ & $3.265 \pm 0.078^{b}$ & $3.943^{*}$ & $<0.05$ \\
\hline WSI & $5.317 \pm 0.202^{\mathrm{a}}$ & $5.237 \pm 0.043^{b}$ & $5.083 \pm 0.108^{c}$ & $0.776^{\mathrm{ns}}$ & 8.488 \\
\hline SPI & $3.654 \pm 0.162^{a}$ & $3.111 \pm 0.060^{b}$ & $3.099 \pm 0.075^{b}$ & $0.478^{* s}$ & $<0.05$ \\
\hline $\mathbf{L}^{*}$ & $30.525 \pm 0.209^{\mathrm{a}}$ & $29.495 \pm 0.360^{\mathrm{a}}$ & $28.425 \pm 0.212^{b}$ & $15.185^{* *}$ & $<0.001$ \\
\hline$a^{*}$ & $9.707 \pm 0.021^{\mathrm{a}}$ & $9.695 \pm 0.070^{\mathrm{a}}$ & $9.137 \pm 0.020^{b}$ & $55.852^{* *}$ & $<0.001$ \\
\hline $\mathbf{b}^{*}$ & $16.22 \pm 0.019^{a}$ & $16.133 \pm 0.057^{\mathrm{a}}$ & $16.032 \pm 0.204^{b}$ & $0.587^{\mathrm{ns}}$ & 0.568 \\
\hline \multicolumn{2}{|c|}{$\begin{array}{l}\mathrm{T}_{1}-0.3 \text { per cent Aloe vera }(\mathrm{AV}) \\
\mathrm{T}_{2}-0.6 \text { per cent Aloe vera }(\mathrm{AV}) \\
\mathrm{T}_{3}-0.9 \text { per cent Aloe vera }(\mathrm{AV})\end{array}$} & $\begin{array}{l}\text { L*- Lightness } \\
a^{*} \text { - Redness } \\
b^{*} \text { - Yellowness }\end{array}$ & \multicolumn{3}{|c|}{$\begin{array}{l}\text { WSI- Water Solubility Index } \\
\text { SPI- Swelling Power Index }\end{array}$} \\
\hline $\begin{array}{l}\text { ns- no } \\
\text { values }\end{array}$ & Hitedis wit & (11pt & S18 & trat & The \\
\hline
\end{tabular}

Table.3 Effect of different level of Pomegranate on ${ }^{(\#)}$ Sensory attributes of instant chicken noodles

\begin{tabular}{|c|c|c|c|c|c|}
\hline Treatments & $\mathbf{T}_{\mathbf{1}}$ & $\mathbf{T}_{\mathbf{2}}$ & $\mathbf{T}_{\mathbf{3}}$ & $\begin{array}{c}\text { Chi-square } \\
\text { Value }\end{array}$ & p- Value \\
\hline $\begin{array}{c}\text { Appearance } \\
\text { and colour }\end{array}$ & $7.208 \pm 0.100$ & $6.875 \pm 0.085$ & $6.375 \pm 0.328$ & $5.737^{\mathrm{ns}}$ & 0.057 \\
\hline Flavour & $7.083 \pm 0.154^{\mathrm{a}}$ & $6.625 \pm 0.085^{\mathrm{b}}$ & $6.292 \pm 0.187^{\mathrm{c}}$ & $7.758^{*}$ & $<0.05$ \\
\hline Taste & $7.167 \pm 0.211^{\mathrm{a}}$ & $6.583 \pm 0.139^{\mathrm{a}}$ & $6.250 \pm 0.171^{\mathrm{c}}$ & $8.176^{*}$ & $<0.05$ \\
\hline Softness & $7.083 \pm 0.154^{\mathrm{a}}$ & $7.000 \pm 0.000^{\mathrm{a}}$ & $6.292 \pm 0.277^{\mathrm{b}}$ & $7.000^{*}$ & $<0.05$ \\
\hline $\begin{array}{c}\text { Stickiness } \\
\text { Mouth } \\
\text { Coating }\end{array}$ & $6.958 \pm 0.136$ & $6.875 \pm 0.085$ & $6.542 \pm 0.187$ & $3.009^{\mathrm{ns}}$ & 0.222 \\
\hline $\begin{array}{c}\text { Overall } \\
\text { acceptabilty }\end{array}$ & $7.208 \pm 0.105$ & $6.708 \pm 0.100$ & $6.917 \pm 0.053$ & $5.745^{\mathrm{ns}}$ & 0.057 \\
\hline
\end{tabular}

$\mathrm{T}_{1}-0.3$ per cent Pomegranate $(\mathrm{PG})$

$\mathrm{T}_{2}-0.6$ per cent Pomegranate (PG)

$\mathrm{T}_{3}-0.9$ per cent Pomegranate (PG)

ns- Non significant. The values are expressed as their Mean \pm Standard error. (Number of observations =24) \# - based on eight point hedonic scales. 1- extremely low and 8- extremely high

\section{References}

Hathway, D. E. (1966). Metabolic fate in animals of hindered phenolic antioxidants in relation to their safety evaluation and antioxidants function. Advances in Food Res. 15, 1. 
official analytical chemists. (19 ${ }^{\text {th }}$ Ed.) AOAC Int., Gaithersburg, USA.

Carbonell, L.A., Lopez. J.F., Perez-Alvarez, J.A and Kuri, V. 2005. Characteristics of beef burger as influenced by various types of lemon albedo. Innov. Food Sci. and Emerg. Technol.6:247-255.

Berry, B.W. and Wergin, W.P. 1992. Modified pregelatinized potato starch in low-fat ground beef patties. $J$. Muscle Foods. 4: 305-320.

Ohishi, K., Kasai, M., Shimada, A. and Hatae, K. 2007. Effects of acetic acid on the rice gelatinization and pasting properties of rice starch during cooking. Food Res. Int.40(2), pp.224231.

Page, J.K., Wulf, D.M. and Schwotzer, T.R. 2001. A survey of beef muscle colour and pH. J. Anim. Sci.79: 678-687.

Sirichokworrakit, S., Phetkhut, J. and Khommoon, A., 2015. Effect of partial substitution of wheat flour with riceberry flour on quality of noodles. Procedia-Social and Behavioral Sci. 197, pp.1006-1012.

Balasundram, N., Sundram, K. and Samman, S. 2006. Phenolic compounds in plants and agri-industrial by-products: antioxidant activity, occurrence and potential uses. Food Chem.99, 191-
203.

Lansky, E.P. \& Newman, R.A. (2007). Punica granatum (pomegranate) and its potential for prevention and treatment of inflammation and cancer. $J$. of Ethno pharmacology, 109, 177-206.

Naveena, B.M., Sen, A.R., Kingsly, R.P., Singh, D.B. and Kondaiah, N., 2008. Antioxidant activity of pomegranate rind powder extract in cooked chicken patties. Int. J. Food Sci. and Technol. 43(10). pp.1807-1812.

Banerjee, R., Verma, A.K., Das, A.K., Rajkumar, V., Shewalkar, A.A. and Narkhede, H.P. 2012. Antioxidant effects of broccoli powder extract in goat meat nuggets. Meat Sci.91(2), pp.179-184.

Wang, R. and Zhou, W. 2004. Stability of tea catechins in bread making process. $J$. of Agriculture and Food Chemistry, 52(26). 8224e8229.

Qin, Y.Y., Zhang, Z.H., Li, L., Xiong, W., Shi, J.Y., Zhao, T.R. and Fan, J. 2013. Antioxidant effect of pomegranate rind powder extract, pomegranate juice, and pomegranate seed powder extract as antioxidants in raw ground pork meat. Food Sci. and Biotech. 22(4). pp.1063-1069.

\section{How to cite this article:}

Pavan, M., T. Sathu, B. Sunil, C. T. Sathian, V. N. Vasudevan, A. Irshad and Kiran Kumar, S. 2019. Effect of Different Level of Natural Antioxidant Pomegranate Peel Extract Powder in Instant Functional Chicken Noodles. Int.J.Curr.Microbiol.App.Sci. 8(10): 1858-1864. doi: https://doi.org/10.20546/ijcmas.2019.810.216 